\title{
ESTRATÉGIAS E ATUAÇÃO DAS CORPORAÇÕES DE AGROTÓXICOS E SEMENTES EM MATO GROSSO: USO CORPORATIVO DO TERRITÓRIO E APROPRIAÇÃO DAS RENDAS DO AGRONEGÓCIO
}

\section{Ana Flávia Marcondes do Amaral ${ }^{1}$}

Resumo: A agricultura científica globalizada é condição para produção de soja no estado de Mato Grosso. Este novo modelo agrícola é dependente de novas tecnologias, principalmente, sistemas técnicos (pacotes tecnológicos - compostos por sementes transgênicas e agrotóxicos). A partir de sua comercialização, corporações de agrotóxico e sementes mantêm uma aliança com o Estado e se apropriam das rendas do agronegócio, exercendo um controle sobre o processo de produção e os produtores. Buscamos compreender poder de influência e controle que essas corporações exercem no território, a partir da comercialização desses sistemas técnicos, analisamos as estratégias utilizadas para apropriação das rendas do agronegócio na região médio-norte do estado de Mato Grosso, que acontece, principalmente, a partir do controle o sistema produtivo.

Palavras-chave: Renda do agronegócio; corporações de sementes e agrotóxicos; sistemas técnicos; produção de soja.

\section{STRATEGIES AND OPERATION OF PESTICIDE AND SEED CORPORATIONS IN MATO GROSSO: CORPORATE USE OF THE TERRITORY AND RENT OF AGRIBUSINESS APPROPRIATION.}

Abstract: Globalized scientific agriculture is a condition for soybean production in the state of Mato Grosso. This new agricultural model is dependent on new technologies, mainly technical systems (technological packages - composed of transgenic seeds and pesticides). From its commercialization, agrochemical and seed corporations hold an alliance with the State and appropriate rent of agribusiness, keeping control over the production process and the farmers. We seek to understand the power of influence and control that these corporations prosecute in the territory, from the commercialization of these technical systems, analyzing the strategies used for appropriation of rent of agribusiness in the mid-northern region of Mato Grosso state, which happens mainly from control of the production system.

Keywords: Rent of agribusiness; seed and pesticide corporations; technical systems; soybean production.

\footnotetext{
${ }^{1}$ Mestranda no Programa de pós- graduação em Geografia UNESP - RIO CLARO. E-mail: anaflaviamarcondesdoamaral@gmail.com
} 


\section{INTRODUÇÃO}

O objetivo principal deste trabalho é demonstrar as estratégias utilizadas pelas corporações de agrotóxicos e sementes para a apropriação das rendas do agronegócio a partir do domínio dos sistemas técnicos na produção de soja na região Médio-Norte em Mato Grosso. Essas corporações são um dos agentes centrais na apropriação da renda do agronegócio na região, especialmente, pela produção de tecnologia para soja e estreita relação com o Estado. O domínio sobre os sistemas técnicos está pautado, principalmente, nos produtos que compõem o pacote tecnológico, sobretudo sementes transgênicas e insumos químicos como, herbicidas, fungicidas, inseticidas e outros.

Renda do agronegócio é um conceito amplo, desenvolvido por loris (2016; 2018), utilizado para explicar a complexidade do processo de produção agrícola pautado no neoliberalismo, onde a renda não deriva apenas da exploração da força de trabalho, sociedade e natureza, mas de uma rede de relações de poder que abrange todo 0 processo de produção, envolvendo o Estado, corporações transnacionais e produtores. A renda do agronegócio caracteriza-se então, como o valor gerado e extraído a partir da totalidade das atividades do agronegócio (principalmente no processo de produção de commodities) que envolve a participação de agentes, sobretudo, o Estado e as grandes corporações. Portanto, é uma ação relacional e política dos agentes que compreende o processo produtivo: Estadocorporação-produtor. (IORIS, 2016; 2018)

As alianças entre esses agentes envolvem intencionalidades e relações de poder, onde o Estado tem papel central, atuando como legitimador, pois é a partir de suas ações e normas que os demais agentes podem atuar no espaço, entendido aqui como "um conjunto indissociável, solidário e também contraditório de sistemas de objetos e sistemas de ações, não considerados isoladamente, mas como o quadro único no qual a história se dá." (SANTOS, 2017 p. 63).

$\mathrm{Na}$ década de 1990 com a consolidação do período técnico cientifico informacional, marcado por reestruturações através do neoliberalismo, globalização e avanço das tecnologias, dá ao espaço um conteúdo crescente de ciência e de técnicas, baseadas em recursos informacionais, gerando novas possibilidades de produção condicionadas principalmente pela circulação e fluidez, de produtos, insumos, capital, informação e ordens (SANTOS; SILVEIRA, 2001; SANTOS, 2008).

O avanço da ciência e das técnicas nesse período impulsionou o desenvolvimento de uma agricultura cientifica globalizada, estimulando o emprego de novas tecnologias para o campo, principalmente as baseadas em biotecnologia pelo uso de sementes transgênicas e insumos químicos; herbicidas, fungicidas e inseticidas (SANTOS, 2008). Essas transformações foram fundamentais para a consolidação do modo de produção atual e para a influência cada vez maior das corporações de agrotóxicos e sementes sobre o processo de produção de commodities. A figura 1 mostra a lista com as dez maiores empresas atuantes no mercado de agrotóxicos e sementes, que pode ser caracterizando como um mercado extremamente oligopolizado. 
Figura 1: Mercado Mundial de Agrotóxicos

Mercado Mundial de Agrotóxicos - 10 maiores empresas (2016)

\begin{tabular}{|c|c|c|c|}
\hline \multicolumn{2}{|r|}{ Empresa } & \multirow{2}{*}{$\begin{array}{c}\text { Vendas de Agrotóxicos } \\
\text { (US\$ bilhões) } \\
9,571\end{array}$} & \multirow{2}{*}{$\begin{array}{c}\text { (\%) do mercado } \\
19,2\end{array}$} \\
\hline $1^{2}$ & Syngenta (Suiça) [China"] & & \\
\hline $2^{3}$ & Bayer CropScience (Alemanha) & 8,810 & 17,6 \\
\hline 3 & BASF (Alemanha) & 6,163 & 12,3 \\
\hline $4 ?$ & Dow AgroSciences (EUA) & 4,631 & 9,3 \\
\hline$S^{2}$ & Monsanto (EUA) & 3,514 & 7,0 \\
\hline 62 & DuPont (EUA) & 2,884 & 5,8 \\
\hline $77^{2}$ & Adama (China) & 2,877 & 5,8 \\
\hline $8^{2}$ & Sumitomo Chemical (Japão) & 2,380 & 4,8 \\
\hline $9^{2}$ & FMC (EUA) & 2,270 & 4,5 \\
\hline $10^{2}$ & UPL (EUA) & 2,157 & 4,3 \\
\hline & Demais & 4,663 & 9,3 \\
\hline & Total & 49,920 & 100 \\
\hline
\end{tabular}

Fonte: AgroNews (http://news.agropages.com/News/NewsDetail--24183.htm)

Fonte: BOMBARDI, L. M. (2017)

O Brasil e o estado de Mato Grosso se destacam perante essas corporações, por sua especialização na produção de commodities agrícolas, principalmente soja. $\mathrm{O}$ Brasil corresponde por vendas entre $11 \%$ e $22 \%$ das 10 maiores empresas do setor (Figura 1), no caso das duas maiores empresas listadas, este percentual foi de aproximadamente $20 \%$ (MORAES, 2019). Por utilizarem da agricultura cientifica globalizada, o país e o estado, são um mercado importante e com relevância mundial para compra dos sistemas técnicos vendidos pelas corporações listadas acima.

Atualmente, o Brasil configura-se como o segundo maior produtor de soja do mundo, com uma área plantada de 35,657 milhões de hectares, com produção de 114,843 milhões de toneladas, atrás apenas dos EUA que possui produção de 123,664 milhões de toneladas e área plantada de 35,657 milhões de hectares (EMBRAPA SOJA, 2019). O estado de Mato Grosso é o maior produtor brasileiro do grão, com área plantada de 9,7 milhões de hectares e produção de 32,4 milhões de toneladas (CONAB, 2019). Nesse contexto, a macrorregião Médio-Norte Matogrossense - divisão estabelecida pelo Instituto Mato-grossense de Economia Agropecuária (IMEA) - destaca-se por possuir a maior produção de commodities agrícolas do estado, onde na safra 2018/2019 foram plantados uma área de 3.254.117 hectares de soja e produção de 11.200 .683 milhões de toneladas do grão (IMEA, 2019), correspondendo respectivamente a cerca de 33\% da área plantada e a $34 \%$ da produção do Estado. Outro ponto de destaque é a presença da rodovia BR-163, utilizada como um dos principais meios de escoamento da safra do Estado.

Este estudo caracteriza-se como uma pesquisa exploratória, com o intuito descritivo analítico. A metodologia utilizada consiste principalmente, no levantamento, organização e análise de bibliografias sobre a temática em livros, jornais, relatórios e artigos científicos, bem como, de dados secundários disponíveis em plataformas digitais como a do MAPA (Ministério da Agricultura, Pecuária e Abastecimento), IBGE (Instituto Brasileiro de Geografia e Estatística), Abrasco (Associação Brasileira de Saúde Coletiva), Aprosoja (Associação dos Produtores de Soja e Milho de Mato Grosso), IMEA (Instituto Mato-grossense de Economia Agropecuária), entre outros.

Este trabalho é resultado de uma pesquisa em andamento, portanto, consiste em uma análise preliminar sobre a temática. Propomos aqui, refletir sobre a atuação e estratégias das empresas de agrotóxico e sementes no território, e a apropriação 
das rendas do agronegócio em Mato Grosso, dessa forma, os resultados aqui a presentados são introdutórios e demandam maior aprofundamento.

\section{CORPORAÇÕES DE AGROTÓXICOS E SEMENTES: OLIGOPOLIZAÇÃO DO MERCADO}

As indústrias de agrotóxicos sempre se apresentaram altamente concentradas mundialmente. Por ser uma atividade determinada pela inovação e tecnologia para diferenciação de produtos (TERRA; PELAEZ, 2008), há um alto risco envolvido por possuir gastos muito elevados e longos prazos para aprovação e liberação de produtos para venda, somente empresas de grande porte são capazes de arcar com os custos referentes à produção dos agrotóxicos (BENETTI, 2002). Portanto, poucas empresas conseguem entrar e se manter no setor, tornando-o concentrado pelas grandes corporações que conseguem superar a rápida obsolescência dos agrotóxicos a partir de elevado investimento em P\&D (pesquisa e desenvolvimento).

O setor de sementes transgênicas ganhou destaque a partir dos anos de 1970, com a revolução da engenharia genética. Assim como na indústria de agrotóxicos, a de sementes transgênicas também demanda elevado investimento em pesquisa e desenvolvimento, dessa forma, somente as grandes companhias de sementes, que possuíam elevados e constantes investimentos, comandavam o setor (MARTINS, 2010). Sendo o domínio que mais acumula conteúdo tecnológico na cadeia produtiva da soja (VIRGÍLIO, 2017). As empresas do setor sempre possuíram lucros elevados através do ganho em cima de propriedades intelectuais derivadas do patenteamento pelo pagamento de royalties.

A partir da relevância e evidência dos OGMs (Organismos Geneticamente Modificados), os governos de países desenvolvidos concederam a empresas privadas uma série de incentivos para o investimento no setor de biotecnologia, gerando um interesse de grandes empresas privadas, principalmente as de agrotóxicos, para atividades de P\&D em cultivos transgênicos. Os motivos que levaram empresas a investirem em biotecnologia, além dos incentivos disponibilizados, foi o fato de estarem buscando novos negócios, e também a previsão de queda no mercado de praguicidas (MARTINS, 2010).

Através da diversificação e ampliação nos investimentos por parte das empresas de agrotóxico, observou-se um processo de fusão e aquisição com as empresas de sementes impulsionados também pela globalização. Esse processo deixou a maior parte das pesquisas em biotecnologia agrícola do setor privado nas mãos de grandes corporações (MARTINS, 2010). Hoje as principais empresas de agrotóxico são também as principais empresas de sementes.

O período de globalização também impulsionou uma série de fusões e aquisições no território brasileiro. Durante a década de 1990, as empresas brasileiras foram adquiridas pelas corporações de agrotóxicos e sementes mundiais (NASCIMENTO JR, 2007). Segundo Virgílio (2017), "de forma extraordinária, e conseguiu, em um pequeno espaço de tempo, não apenas se consolidar no país, mas se tornar hegemônico, exercendo um poder de mercado expressivamente alto" (p.73). As corporações buscavam uma oportunidade de se expandir e adquirir parte do mercado brasileiro, aumentando a sua concentração e as barreiras à entrada de novos competidores (VIRGÍLIO, 2017), as fusões e aquisições contribuíram para uma concentração ainda maior do setor, nacional e mundialmente.

Formou-se um núcleo extremamente oligopolizado, que se intensificou a partir de 2016, houve pelo menos três grandes fusões/aquisições entre as empresas 
listadas na figura 1. Destaca-se a fusão entre a Dow e DuPont; a compra da Monstanto pela Bayer (AENDA, 2017) e a aquisição da Syngenta e Adama pela ChemChina (AENDA, 2017; BOMBARDI, 2017). O processo de oligopolização fica mais evidente com a informação de que, em 2019, Syngenta/Adama, Bayer, Corteva (Dow/DuPont), BASF e FMC controlavam 70\% do mercado brasileiro (AENDA, 2017).

O processo de concentração do mercado provocou uma intensificação na realização de projetos em P\&D de tecnologias para patenteamento. O domínio sobre as inovações tecnológicas é uma estratégia adotada pelas corporações de agrotóxicos e sementes que demostra o controle sobre o mercado e uma vantagem competitiva sobre as concorrentes do setor. O patenteamento contribui para o controle sobre a produção e o produtor, sendo um instrumento de poder econômico exercido por elas.

Os direitos de propriedades intelectuais criam "monopólios do conhecimento" já que os donos das patentes podem determinar tanto o uso de sua invenção quanto a comercialização dos produtos que as contêm. As patentes, ao restringirem o acesso e uso da invenção garantem direitos aos inventores e financiadores de pesquisas, permitem a esses o controle do preço de suas invenções podendo até mesmo impedir novas descobertas científicas." (MARTINS, 2010, p. 106)

Segundo Ribeiro (2003), aproximadamente dois terços dos produtos patenteados nunca chegam ao mercado ou a serem fabricados, tendo como objetivo proteger outras patentes, reforçando os monopólios já existentes e garantindo o pagamento de royalties. Estima-se que os produtores de soja em Mato Grosso tenham pago cerca de $R \$ 916,079$ milhões em royalties na safra $2017 / 2018$, para cada hectare foram cobrados entre $R \$ 139$ a $R \$ 162$ pelo direito de uso de tecnologias (APROSOJA, 2017).

\section{QUESTÃO DA PRODUÇÃO AGRÍCOLA EM MATO GROSSO}

A especialização de Mato Grosso no cultivo de commodities se deu a partir de um contexto histórico e geográfico, pautado em interesses de mercado, políticos e sociais, que ocorreu a partir da década de 1990 com o processo de internacionalização da produção, ajustes tecnológicos, assim como, o avanço em pesquisas na biotecnologia, engenharia genética, informática e aumento das exportações de produtos primários (FREDERICO, 2013b). É nesse contexto que a produção de soja no estado ganha destaque e se torna substancial.

A dependência estatal por moeda estrangeira para atender demandas macroeconômicas e o surgimento de uma série de condições adequadas à exportação com taxas de câmbio favoráveis, contribuíram para a proporção que a cultura possui na atualidade, e sua importância econômica para o país.

Houve poucas mudanças nas bases da agricultura da região, sempre pautadas no latifúndio, monocultura, uso intensivo de agrotóxicos, tecnologias e máquinas (IORIS, 2016). Na fase atual, o Estado deixa de operar como regulador da agricultura, sendo substituído pela atuação das grandes corporações transnacionais do comércio de grãos, agroindustriais e de agroquímicos, que cada vez mais, financiam a produção e a infraestrutura agrícola. O papel do Estado se tornou mais indireto ficando responsável pela inserção do Brasil nos mercados globais e na construção de infraestrutura logística (FREDERICO, 2013b; IORIS, 2016). Como 
exemplo, o crédito rural financiado pelo Estado foi de 64\% em 1985, 22\% em 1994 e apenas 3,5\% em 1996 (e cerca de 8\% em 2008). (IORIS, 2016)

A reestruturação do período ofereceu novas possibilidades para a acumulação de capitais (ELIAS, 2013) para as corporações transnacionais, a partir da apropriação das rendas do agronegócio da região (IORIS, 2016; 2018). As corporações passaram a operar de forma mais incisiva em toda cadeia produtiva.

O modelo de produção da região demanda um elevado grau de dependência dos sistemas técnicos (sementes transgênicas e agrotóxicos) fundamentado em altos níveis de produção e rentabilidade, assim como de financiamentos públicos e privados, através das corporações de agrotóxicos e sementes que comandam desde a concessão de crédito, compra de sementes, até a forma de uso e manejo do solo. Dessa forma, a maneira que se dá o processo produtivo, é imposto e comandado pelos interesses hegemônicos das grandes corporações transnacionais (SANTOS, 2008). Esse modelo de produção engessa o produtor e estimula a conservação da estrutura fundiária, já que apenas os produtores mais capitalizados conseguem se sustentar nessa estrutura.

\section{APROPRIACCÃO DA RENDA DO AGRONEGÓCIO E USO CORPORATIVO DO TERRITÓRIO}

O estado de Mato Grosso e principalmente, a macrorregião Médio-Norte, se destaca perante as corporações de agrotóxico e semente, pela produção de soja. Como reflexo disso, concentra elementos que demonstram o uso corporativo do território exercido por essas corporações, não só durante o processo produtivo, mas também, a partir de serviços técnicos, cursos superiores, institutos e centros de pesquisa públicos (EMBRAPA) e particulares associados a essas corporações.

O uso corporativo do território se estabelece a partir da forma como essas corporações utilizam e produzem o território de acordo com seus interesses, há a imposição de uma nova lógica (SILVEIRA, 2011). Assim, o Brasil, a partir de sua centralidade na produção de soja é um dos focos desse interesse corporativo, destacando-se por ser um dos maiores mercados consumidores e importadores de agrotóxicos do mundo (BOMBARDI 2011; PELAEZ et al, 2016) impulsionado pelo uso de sementes transgênicas (IORIS, 2016).

Segundo Bombardi (2017), o consumo total de agrotóxicos no Brasil cresceu $135 \%$ entre os anos de 2000 a 2014 , passando de 170 mil toneladas para 500 mil toneladas, respectivamente, sendo a cultura de soja o destino de $52 \%$ das vendas. Entre os Censos Agropecuários (IBGE) de 2006 e 2017, houve um crescimento de $20,4 \%$ no número de estabelecimentos que usam agrotóxicos no Brasil. Em Mato Grosso, o número de estabelecimentos agropecuários que utiliza agrotóxico ou que utiliza, mas não estava usando no momento da pesquisa, é de 53.776 mil estabelecimentos (IBGE, 2017). Vale ressaltar que há uma concentração de unidades produtivas dessas corporações nos principais mercados consumidores, o Brasil conta com 15 filiais das seis empresas líderes do mercado (Figura 1), destaca-se que essas empresas detêm cerca de $70 \%$ do mercado mundial de agrotóxicos (PELAEZ et al. 2016). A figura 2 mostra a quantidade de agrotóxico utilizada por estado: 
Figura 2: O uso de agrotóxicos e a quantidade utilizada por Unidades da Federação entre os anos de 2012 e 2014.

\section{BRASIL USO DE AGROTÓXICOS \\ QUANTIDADE UTILIZADA}

Unidades da Federeção (2012 - 2014)

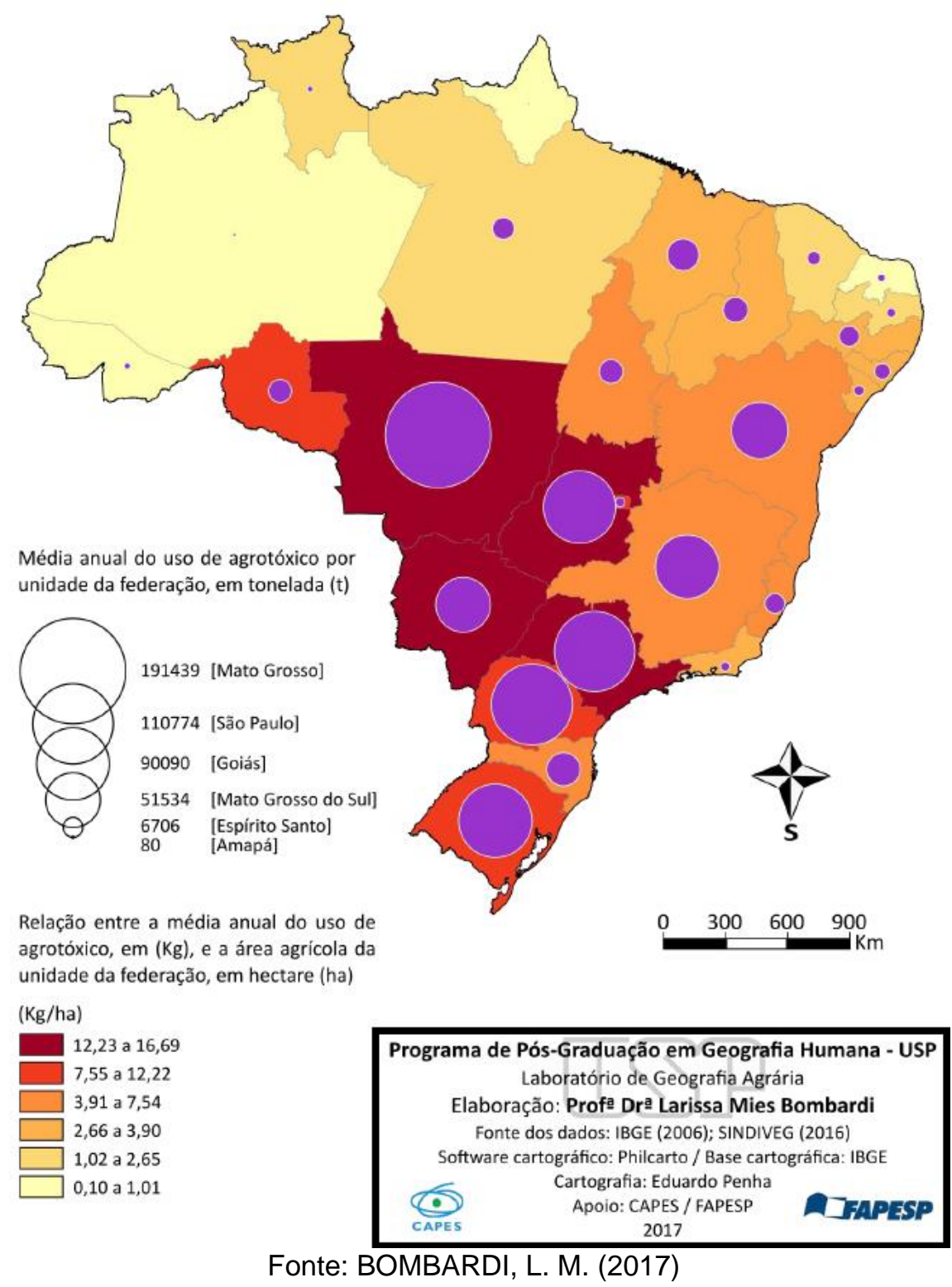

Mato Grosso configura-se como o estado que mais usa agrotóxico e que também utiliza o maior volume por hectare. O aumento no consumo de agrotóxicos está relacionado à expansão do cultivo de sementes transgênicas, apontando uma complementaridade para manter e ampliar significativamente os mercados dessas corporações. Segundo Goodman; Sorj; Wilkinson (2008) "os novos cultivares novamente formarão o núcleo de 'pacotes tecnológicos', mas as sementes originárias da engenharia genética garantirão que os fazendeiros ficarão muito mais presos aos agroquímicos patenteados." (p.96).

O desenvolvimento das novas tecnologias genéticas e químicas possibilitou a utilização de tecnologias similares nos produtos e a venda casada destes. A complementaridade entre os produtos expressa uma característica fundamental do 
período técnico cientifico informacional, baseado no uso corporativo do território, a unicidade dos sistemas técnicos hegemônicos (SANTOS, 2008). É através da existência de uma família de produtos que os sistemas técnicos são comercializados, garantindo uma adequação dos produtos.

Em 2019, 93\% da plantação de soja, milho e algodão no Brasil foi transgênica, correspondendo a uma área de 53,1 milhões de hectares, só de soja, foram 34,86 milhões de hectares, contribuindo para que o país se tornasse líder no plantio mundial da oleaginosa (CÉLERES, 2019). Em Mato Grosso, a soja geneticamente modificada ocupa 9,07 milhões de hectares, correspondendo à área quase total da produção do grão, 99,3\%, (CIB, 2017).

As tecnologias desenvolvidas são inseridas nos sistemas técnicos, além de aumentar a produtividade no cultivo de soja, aumenta os custos de produção. Entre as safras 2014/2015 e 2018/2019 houve um aumento de $46 \%$ nos custos de produção com sementes e insumos, ao passo que o número de sacas por hectare aumentou apenas $9 \%$, os gastos totais com a produção nesse período apresentaram um aumento de $31 \%$ (IMEA, 2019). Na safra 2018/2019, 1/3 dos gastos corresponderam à compra de sementes e agrotóxicos, cerca de 32\% do custo total (APROSOJA, 2019). De forma direta, essas corporações se apropriam de $32 \%$ da renda do agronegócio da produção, podendo ser ainda maior se considerarmos a totalidade das atividades do agronegócio que essas corporações estão envolvidas e as contínuas isenções fiscais que o setor possui.

O uso corporativo do território possui uma nítida expressão política. Essas corporações influenciam diretamente o processo regulatório, estimulando a criação e a alteração de leis para que elas sejam mais brandas para a liberação de produtos e patentes, se articulam com atores da sociedade buscando isenções fiscais, redução de carga tributária e redução do poder decisório de agências reguladoras, entre outros (MORAES, 2019). A formulação de políticas é muitas vezes afetada pelas corporações que buscam manipular o processo político de acordo com seus interesses (IORIS, 2016; 2018).

O Estado no que the concerne, pactua com os interesses das corporações, sendo um reflexo da articulação entre esses agentes. Como exemplo houve a alteração na Lei de Biossegurança ${ }^{2}$ em 2005, que permitiu o cultivo de transgênicos; a Lei Kandir ${ }^{3}$ de 1996, que isenta produtos primários da cobrança de ICMS para exportação, há também a Lei de incentivo fiscal a agrotóxicos ${ }^{4}$, de 2004 e o Convênio no 100/975 - CONFAZ, que prevê a redução ou mesmo eliminação de impostos diversos sobre a comercialização de agrotóxicos, como o ICMS, IPI, Contribuições Sociais (Cofins e PIS/PASEP) e o imposto sobre importações. Atualmente são diversos os exemplos de articulação entre o Estado e Corporações, indo além dos mencionados.

Segundo o relatório ABRASCO (2020), os benefícios fiscais concedidos aos agrotóxicos se aproximaram de 10 milhões de reais em 2017. Como demonstrado na tabela a seguir elaborada pela mesma instituição.

\footnotetext{
2 Lei $\mathrm{n}^{\mathrm{o}}$ 11.105, de 24 de mar. de 2005. Brasília, DF, 24 mar. 2005. Disponível em: https://www.planalto.gov.br/ccivil_03/_ato2004-2006/2005/lei/111105.htm.

3 Lei complementar $\mathrm{N}^{\circ}$ 87, de 13 de set. de 1996. Brasília, DF, 16 set. 1996. Disponível em: https://www.planalto.gov.br/ccivil_03/leis/lcp/lcp87.htm.

4 Lei $\mathrm{n}^{\mathrm{o}}$ 10.925, de 23 de jul. de 2004. Brasília, DF, 26 jul. 2004. Disponível em: https://www.planalto.gov.br/ccivil_03/_ato2004-2006/2004/lei/110.925.htm.

${ }^{5}$ Confaz no 100/97, de 04 de nov. de 1997. Brasília, DF, 06 nov. 1997. Prorrogado, até 31.12.20. Dis ponível em: https://www.confaz.fazenda.gov.br/legislacao/convenios/1997/CV100_97.
} 
Figura 3: Estimativas de incentivos fiscais a agrotóxicos

Tabela 1 - Estimativas de Incentivos Fiscais aos agrotóxicos na República

Federativa do Brasil, segundo competência e tributos (2017)

\begin{tabular}{|c|c|c|c|c|}
\hline $\begin{array}{l}\text { Competência } \\
\text { Tributária }\end{array}$ & Tributos & $\begin{array}{l}\text { Desoneração| } \\
\text { (milhões R\$) }\end{array}$ & $\begin{array}{l}\% \text { Segundo } \\
\text { Competência }\end{array}$ & $\begin{array}{l}\text { \% Segundo } \\
\text { Tributo }\end{array}$ \\
\hline \multirow{3}{*}{ União } & $\begin{array}{l}\text { Pis- } \\
\text { Pasep/Cofins }\end{array}$ & $1.536,22$ & \multirow{3}{*}{35,4} & 15,6 \\
\hline & IPI & $1.623,52$ & & 16,5 \\
\hline & $\begin{array}{l}\text { Imposto } \\
\text { Importação }\end{array}$ & 472,62 & & 4,8 \\
\hline Estados e DF & ICMS & 6222,64 & 63,1 & 63,1 \\
\hline \multicolumn{2}{|c|}{ Brasil (Total) } & 9855,00 & 100 & 100 \\
\hline
\end{tabular}

Fonte: ABRASCO (2020)

Segundo Moraes (2019) há a construção de uma narrativa de legitimidade por parte dessas corporações para atender a seus interesses. Elas recorrem ao seu poder econômico e político para a mobilização de setores da sociedade como: associações de empresas e produtores, políticos (bancada ruralista), propagandas na mídia, financiamento de pesquisas, cientistas e laboratórios para corroborar a importância e eficácia de seus produtos, entre outras estratégias. Essas narrativas de legitimidade também servem para desacreditar e deslegitimar pesquisas e enfraquecer os processos regulatórios e fiscais sobre o setor. As narrativas de legitimidade constroem um imaginário coletivo a favor das corporações.

A atuação das corporações passou a ir além da oferta, produção e desenvolvimento dos sistemas técnicos, operando, também, no fornecimento de crédito agrícola aos produtores, expandindo sua influência sobre a área financeira. Atualmente grande parte do crédito fornecido vem de multinacionais de agroquímicos, cerca de $30 \%$ na safra 18/19 (IMEA, 2019).

Dessa forma, há uma dependência do produtor ao crédito fornecido por essas corporações, demonstrando certa vulnerabilidade. Destaca-se que o financiamento da produção por essas empresas, muitas vezes está condicionada à compra de seus sistemas técnicos. O Estado também condiciona o fornecimento de crédito para a agricultura familiar, através do Programa Nacional de Fortalecimento da Agricultura Familiar (PRONAF) ao uso de pacotes tecnológicos, incluindo a necessidade de utilização de agrotóxicos (MORAES, 2019). As corporações de agrotóxicos e sementes continuamente exercem um controle crescente sobre o produtor e os meios de produção, onde ele se encontra preso a poucas opções de fornecedores.

Nesse contexto, as corporações de agrotóxicos e sementes, garantem mais uma forma de se apropriar das rendas do agronegócio na produção de soja em Mato Grosso, se tornando um dos agentes principais nesse processo, pois estabelecem um uso corporativo do território (SILVEIRA, 2011) sobre a região de acordo com deus interesses. Elas possuem grande poder econômico e político; sobre o Estado, os produtores e a produção, atuando em uma parcela cada vez maior do processo produtivo, desde o desenvolvimento e produção de tecnologias, até a venda dos insumos e financiamentos. 


\section{CONSIDERAÇÕES FINAIS}

Este trabalho buscou compreender as formas de atuação das corporações de agrotóxicos e sementes no território nacional e, como estas se apropriam de recursos e riquezas brasileiras visando à apropriação das rendas do agronegócio para maximização de seus lucros e suas consequências para a autonomia brasileira perante o sistema econômico mundial. Esse controle exercido por elas coloca em risco a soberania nacional sobre o território, meios de produção e sua condição ambiental.

A agricultura cientifica globalizada fundamentada na apropriação das rendas do agronegócio e no uso intensivo de sistemas técnicos, eleva os custos de produção e o domínio de grande parte do processo de produção e comercialização pelo capital internacional. De forma geral, a atuação das corporações aprofundou a dependência tanto dos produtores, como da economia brasileira aos interesses dos países centrais, reprimarizando a economia e aumentando sua vulnerabilidade externa (VIRGÍLIO, 2017).

As corporações de agrotóxicos e sementes ainda são uma das principais promotoras do modelo de produção atual. É através do domínio sobre sistemas técnicos que elas conseguem elevar suas receitas ano a ano. O Brasil tem papel central nesse modelo de produção, devido à sua posição na divisão internacional do trabalho, sendo um mercado fundamental para a manutenção de seus lucros.

Com base na conjuntura demonstrada até aqui, a renda do agronegócio gerada na produção de soja é apropriada pelas empresas de agrotóxicos e sementes a partir de grande parte do processo produtivo pelo uso de sistemas técnicos, para isso elas empregam diversas estratégias através do uso corporativo do território, com base na relação Estado-Corporação-produtor (aliança base para a apropriação das rendas do agronegócio). Fundamentado nas reflexões feitas, foram consideradas como estratégias utilizadas: dependência dos produtores, controle sobre o sistema de produção, concessão de crédito, oligopolização do mercado, controle sobre a tecnologia e a intensa relação e associação com o Estado.

\section{REFERÊNCIAS}

ABRASCO. Uma política de incentivo fiscal a agrotóxicos no Brasil é injustificável e insustentável. 2020. 48 p. Disponível em: https://apublica.org/wpcontent/uploads/2020/02/relatorio-abrasco-desoneracao-fiscal-agrotoxicos12022020.pdf. Acesso em: 15 jun. 2020.

AENDA, Associação Brasileira dos Defensivos Genéricos. As 20 maiores empresas agroquímicas brasileiras em 2017. 2017. Disponível em: <https://www.aenda.org.br/midias_post/as-20-maiores-empresas-agroquimicasbrasileiras-em-2017/>. Acesso em: 29 ago. 2019.

\section{AGRONOTÍCIAS MT. Produtores mato-grossenses pagam R\$ 916 milhões em royalties para plantar soja. 2017. Disponível em: $<$ https://www.agrolink.com.br/noticias/produtores-mato-grossenses-pagam-r--916- milhoes-em-royalties-para-plantar-soja_401403.html>. Acesso em: 02 set. 2019.}


APROSOJA. Custo de Produção de Soja safras 18/19 - 19/20. Mato Grosso: Aprosoja Brasil, 2019. Disponível em: https://aprosojabrasil.com.br/wpcontent/uploads/2019/05/4-CUSTOS-18.19_19.20.pdf. Acesso em: 20 jun. 2020.

BENETTI, Maria D.. Reestruturação das indústrias de suprimentos agrícolas no Brasil, nos anos 90: concentração e desnacionalização. Indic. Econ. FEE, Porto Alegre, v. 30, n. 1, p.137-166, jun. 2002.

BOMBARDI, Larissa Mies. Intoxicação e morte por agrotóxicos no Brasil: a nova versão do capitalismo oligopolizado. In: Boletim Dataluta. NERA - Núcleo de Estudos, Pesquisas e Projetos de Reforma Agrária. Presidente Prudente, Setembro de 2011, p. $1-21$.

BOMBARDI, Larissa Mies. Geografia do Uso de Agrotóxicos no Brasil e Conexões com a União Europeia. São Paulo: FFLCH - USP, 2017.

CÉLERES. Informativo de biotecnologia céleres. Uberlândia: Céleres, 2019. 5 p. Disponível em: http://www.celeres.com.br/wpcontent/uploads/2019/11/BoletimBiotecnologiaC\%C3\%A9leres_Novembro20192.pdf. Acesso em: 20 jun. 2020.

$\mathrm{CIB}$, Conselho de Informações sobre Biotecnologia. Mato Grosso é destaque mundial na adoção de biotecnologia agrícola. Disponível em: $<$ https://cib.org.br/mato-grosso-e-destaque-mundial-na-adocao-de-biotecnologiaagricola/>. Acesso em: 29 ago. 2019.

ELIAS, Denise. Globalização, agricultura e urbanização no Brasil. Revista Acta Geográfica, [s...], p.13-32, Revista ACTA Geografica. 2013.

EMBRAPA SOJA. Soja em números: (safra 2018/19). (safra 2018/19). 2019. Disponível em: <https://www.embrapa.br/soja/cultivos/soja1/dados-economicos>. Acesso em: 26 maio 2020.

FREDERICO, Samuel. Modernização da Agricultura e Uso do Território: A Dialética Entre o Novo e o Velho, o Interno e o Externo, o Mercado e o Estado em Áreas de Cerrado. Geousp: Espaço e Tempo, São Paulo, n. 34, p.46-61, 2013a.

FREDERICO, Samuel. Agricultura científica globalizada e fronteira agrícola moderna no Brasil. Confins, [s.I.], n. 17, 16 mar. 2013b.

GOODMAN, D., SORJ, B., WILKINSON, J. Da lavoura às biotecnologias: agricultura e indústria no sistema internacional. Rio de Janeiro: Centro Edelstein de Pesquisas Sociais, 2008. 204 p.

HERMIDA, Camila; PELAEZ, Victor. A Industria de Agrotóxicos no Brasil: O debate em torno da Lei sobre informações não divulgadas. Revista de Políticas Públicas, São Luís, v. 5, n. 1, p.63-75, jan/jun. 2011.

IORIS, Antonio R. Rent of agribusiness in the Amazon: A case study from Mato Grosso. Land Use Policy, [s.I.], v. 59, p.456-466, dez. 2016. 
IORIS, Antonio Augusto Rossotto. Interrogating the Advance of Agribusiness in the Amazon: production, rent and politics. Rev. Nera, Presidente Prudente, v. 21, n. 42, p. 74-97, jun. 2018.

IMEA. Custo de produção da soja - safra 2018/19. 2019. Disponível em: <http://www.imea.com.br/imea-site/\#>. Acesso em: 02 set. 2019.

IMEA. Custo de produção de soja - safra 2014/2015. 2019. Disponível em: <http://www.imea.com.br/imea-site/\#>. Acesso em: 02 set. 2019.

IMEA. Composição do funding do custeio da soja para safra 2018/19 em Mato Grosso. 2019. Disponível em: <http://www.imea.com.br/imea-site/\#>. Acesso em: 02 set. 2019.

MARTINS, Aline Regina Alves. Dependência e monopólio no comércio internacional de sementes transgênicas. 2010. 150 f. Dissertação (mestrado) UNESP/UNICAMP/PUC-SP, Programa San Tiago Dantas, 2010.

MORAES, Rodrigo Fracalossi de. Agrotóxicos No Brasil: Padrões De Uso, Política Da Regulação E Prevenção Da Captura Regulatória. Texto para discussão oㅡ 2506 Instituto de Pesquisa Econômica Aplicada. Rio de Janeiro, Ipea, 2019.

NASCIMENTO JÚNIOR, Francisco das Chagas do. Aconstituição do círculo de cooperação de pesquisa agrícola no brasil: nova face do uso corporativo do território brasileiro no período técnico-científico-informacional. 2007. $138 \mathrm{f}$. Dissertação (Mestrado) - Curso de Geografia, Unesp, Rio Claro, 2007.

PELAEZ, Victor et al. A dinâmica do comércio internacional de agrotóxicos. Revista de Política Agrícola, Brasília/DF, v. 25, n. 2, p.39-52, 2016.

RIBEIRO, Silvia. Camponeses, biodiversidade e novas formas de privatização. In: CARVALHO, Horacio Martins de et al. Sementes: Patrimônio do povo a serviço da humanidade. São Paulo: Expressão Popular, 2003. p. 51-72.

SILVEIRA, Maria Laura. Território usado: dinâmicas de especialização, dinâmicas de diversidade. Ciência Geográfica, Bauru, v. 15, n. 1, p. 4-12, jan/dez, 2011.

SANTOS, Milton. A Natureza do Espaço: técnica e tempo. razão e emoção. 4. ed. São Paulo: Edusp, 2017.

SANTOS, Milton. Técnica, Espaço, Tempo: Globalização e Meio Técnico-científicoinformacional. 5. ed. São Paulo: Edusp, 2008.

SANTOS, Milton; SILVEIRA, Maria Laura. O Brasil: território e sociedade no início do século XXI. São Paulo, Editora Record, 2001.

TERRA, F. H. B. e PELAEZ, V. A evolução da indústria de agrotóxicos no Brasil de 2001 a 2007: a expansão da agricultura e as modificações na lei de agrotóxicos. XLVI Congresso da Sociedade Brasileira de Economia, Administração e Sociologia Rural. 2008. 
VIRGÍLIO, Aline Patrícia Santos. Agricultura moderna brasileira e aprofundamento da dependência a partir dos anos 1990: o caso do agronegócio da soja. 2017. 123 f. Dissertação (Mestrado) - Curso de Economia, Universidade Federal da Bahia, Salvador, 2017.

WILKINSON, J. (Coord.) \& CASTELLI, P. G.A transnacionalização da indústria de sementes no Brasil: biotecnologias, patentes e biodiversidade. Rio de Janeiro: ActionAid Brasil, 2000. 138p. 